\title{
Reliability and Validity of Dental Arch Measurements Obtained from Photographs and Scanned Images of Dental Casts with that of Conventional Dental Cast
}

\author{
Kuldeep Jaryal' ${ }^{1}$, Anil Singla ${ }^{2}$, Col S K Rath ${ }^{3}$, Vivek Mahajan² \\ ${ }^{1}$ Department of Orthodontics, Dentistry Zonal Hospital, Dharamshala, Himachal Pradesh, India, ${ }^{2}$ Department of Orthodontics, \\ Himachal Dental College, Sundar Nagar, Himachal Pradesh, India, ${ }^{3}$ Commanding Officer, 9 Corps Dental Unit, Yol Cantt, India
}

Email for correspondence: kuldeepjaryal21@gmail.com

\begin{abstract}
Context: Successful orthodontic treatment is based on comprehensive diagnosis and treatment planning Study casts have always been important in orthodontics. They are a tool of basic diagnosis that can tell us about the patient's occlusion in 3 planes of space. This information is useful when making a diagnosis and planning orthodontic treatment Aims and Objectives: The purpose of this study was to evaluate the reliability and validity of dental arch measurements obtained from photographs and scanned images of dental casts with that of the conventional dental cast. Materials and Methods: The study comprised of 50 patients (25 males and 25 females) aged 15-24 in permanent dentition without agenesis and/or tooth loss. Twenty-eight variables were examined. Results: A paired $t$-test and interclass correlation coefficient (ICC) were used to evaluate validity and reliability. ICC revealed excellent reliability for photographic methods $(P<0.05)$. Conclusion: Photographs seems to be a clinically acceptable alternative to stone casts for the routine measurements used in orthodontic practice.
\end{abstract}

Key words: Photographs, reliability, scanned images

\section{INTRODUCTION}

Successful orthodontic treatment is based on comprehensive diagnosis and treatment planning. ${ }^{[1]}$ Study casts have always been important in orthodontics. They are a tool of basic diagnosis that can tell us about the patient's occlusion in 3 planes of space. This information is useful when making a diagnosis and planning orthodontic treatment. ${ }^{[2]}$ The need for suitable storage and the risk of fracture are considered disadvantages when using dental casts as orthodontic records. Another

\section{Quick Response Code Article Info:}

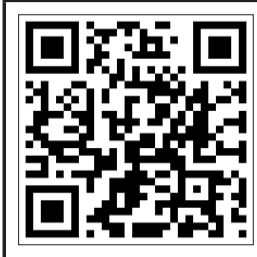

doi: $10.5866 / 2017.9 .10152$

Received: 01-08-2017

Revised: 07-09-2017

Accepted: 14-09-2017

Available Online: 27-11-2017 (www.nacd.

in)( NAD, 2017 - All rights reserved limitation is difficulty involved in accessing models To avoid such disadvantages, dental casts have been reproduced in two dimensions through photographs and photocopies. ${ }^{[3]}$

Recently, advances in digital technology have resulted in new three-dimensional methods. However, dental cast scanning seems to be the only option for eliminating model storage while providing reliable dental cast analysis. Few alternatives have been presented to reduce the need to obtain dental casts. ${ }^{[4]}$ Today, many orthodontists are moving toward digitizing orthodontic records and using computers to assist with diagnosis and treatment planning. ${ }^{[5]}$ Proffit stated that one advantage of digitizing tooth dimensions for space analysis is that the computer can quickly provide a tooth-size analysis. ${ }^{[6]}$

In addition to its relatively high initial costs, laser intraoral scanning requires further studies 
to confirm its accuracy. Due to improvements in the quality and low cost of images obtained with digital cameras, one possibility involves obtaining tooth size and dental arch measurements from intraoral images. Although occlusal photographs taken using an orthoscan camera, it was observed that the measurements obtained from these images were reliable. ${ }^{[7]}$ However, there was a need for more detailed investigations to test the accuracy and reliability of this method. Hence, the objective of this study was to evaluate reliability and validity of dental arch measurements obtained from photographs and scanned images of dental casts with that of the conventional dental cast.

\section{MATERIALS AND METHODS}

The present study was conducted in the Department of Orthodontics and Dentofacial Orthopaedics, Himachal Dental College and Hospital, Sunder Nagar (Himachal Pradesh). The study comprised of 50 patients, 25 male and 25 female.

The inclusion criteria were as follows:

a. Well-balanced and pleasing facial profile.

b. No previous history of orthodontic treatment.

c. No history of trauma, plastic surgery, or orthognathic surgery.

d. Aged between 15 and 24 years (mean 18.3 years).

e. In permanent dentition without agenesis and/or tooth loss.

\section{Photographic technique}

The occlusal photographs were obtained with a 10 megapixels digital camera (model D-40, Nikon, Tokyo, Japan) with an $105 \mathrm{~mm}$ macro lens at the closest focusing distance of $120 \mathrm{~mm}$. The importance of $105 \mathrm{~mm}$ macro lens is that a high-quality lenses assure a maximum depth of field, with the smallest possible distortion and minimal alteration of colors. Flat occlusal mirrors were used to obtain the occlusal photographs. One standardized occlusal photograph of the upper and lower dental arches was obtained for each individual. The mirror was positioned in contact with the opposite dental arch to that being photographed, and 45 to the occlusal plane as this provides a 90 view of the area of interest. The camera was positioned perpendicular to the occlusal plane so that the front teeth were viewed at their incisal edges. At least the first molar should be visible on the picture, and ideally, all erupted teeth should be visible. To fulfil these requirements, maximal mouth opening by the patient is essential. For the pictures of the lower jaw, the tongue was elevated to the hard palate and gently pushed back out of view with the mirror. Special attention was given to avoid tilting the mirror or the camera. In addition to prevent movement of the buccinator muscle and lips, an acrylic lip retractor was used [Figure 1]. An occlusal ruler was bonded on the acrylic retractor to allow dental arch images to be measured with the aid of digital software [Figure 2]. Mesiodistal tooth widths and dental arch dimensions were measured. The casts were scanned with HP Scanjet 3570 scanner with a ruler to allow dental arch images to be measured with the aid of digital software [Figure 3]. The obtained images were exported to Image Tool software, a free image processing and analysis program. Using this software, it was possible to obtain linear measurement in pixels

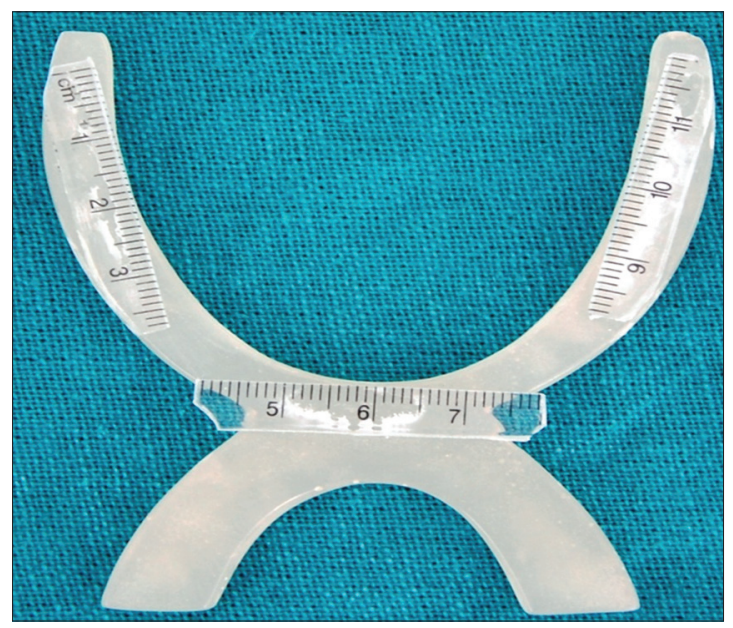

Figure 1: Acrylic lip retractor with occlusal ruler

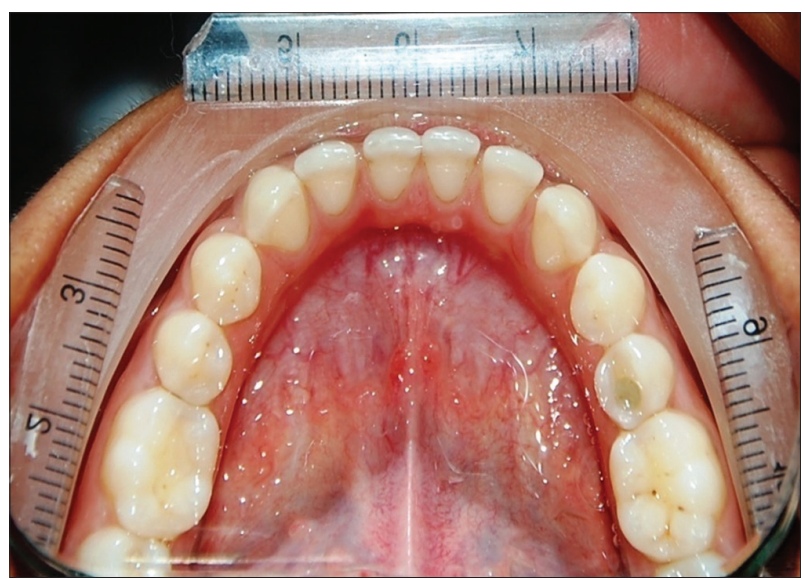

Figure 2: Occlusal image of the dental arch with occlusal millimeter ruler 


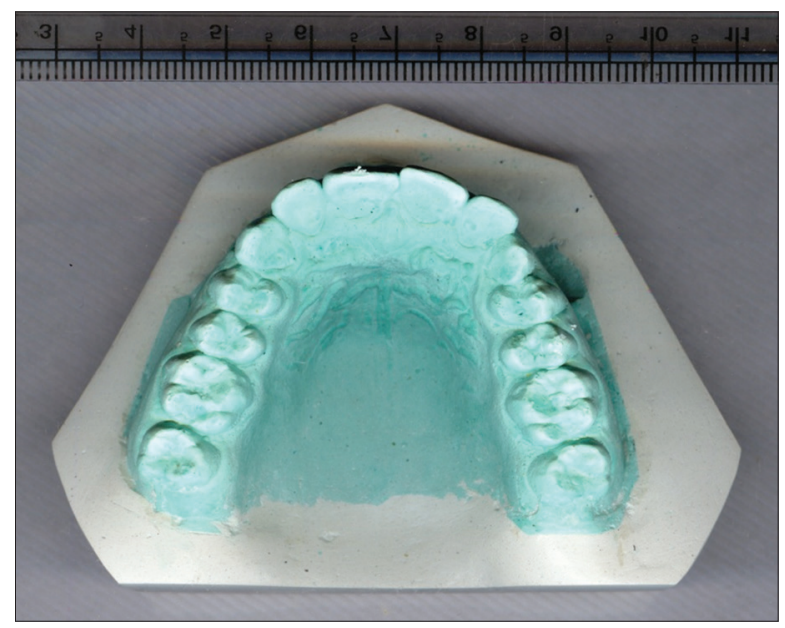

Figure 3: Scanned image of dental cast with millimeter ruler

(the smallest photographic element). Initially, the number of pixels in $1 \mathrm{~cm}$ of the occlusal ruler was read. A straight, $1 \mathrm{~cm}$ segment of the image measured in pixels was used as a parameter to convert the number of pixels in the real image to centimeters. Thus, all measurements obtained in pixels through the image tool software were converted to millimeters using cross-multiplication. The measurements from dental casts for each subject were obtained using a digital calliper with $0.01 \mathrm{~mm}$ sensitivity. Twenty-eight variables were examined. The photographic measurements and scanned images of each subject were compared with values obtained from the models.

\section{RESULTS}

Mean, standard deviation, standard error, mean difference and interclass correlation coefficient (ICC) between cast, photograph, and scanned images of dental cast were evaluated with the SPSS 11.5 Software. Reliability was evaluated with the ICC while validity was examined with the paired $t$-test. The range of measurements for dental width obtained from the dental cast were ranged from 5.29 to $10.69 \mathrm{~mm}$, and measurements for dental arch dimensions obtained from the dental cast were ranged from 25.79 to $50.21 \mathrm{~mm}$.

The range of measurements for dental width obtained from dental photographs were ranged from 5.14 to $10.47 \mathrm{~mm}$, and measurements for dental arch dimensions obtained from dental photographs were ranged from 25.53 to $49.73 \mathrm{~mm}$.

The range of measurements for dental width obtained from scanned images of dental cast were ranged from 5.22 to $10.57 \mathrm{~mm}$, and measurements for dental arch dimensions obtained from the same were ranged from 25.71 to $49.86 \mathrm{~mm}$.

When all the dental width measurements were compared, the excellent correlation were found with r values ranging from 0.82 to 0.97 between dental cast photographic and scanned images measurements. When intercanine width was compared between three methods, the correlation was also excellent with $r$ values ranging from 0.98 to 0.99 , and when the intermolar widths were compared between three methods, the correlation was excellent with $r$ values ranging from 0.97 to 0.99 .

\section{DISCUSSION}

Vernier caliper is used to measure teeth and complete a tooth size analysis. Although it involves much less time than diagnostic setups, manual tooth-size analysis can be time-consuming in a busy practice, as well as prone to recording and calculation errors. ${ }^{[8]}$ In fact, other than looking at the lateral incisors, many clinicians probably do not routinely measure tooth-size discrepancies. The present study was designed to determine if newer computerized methods were equally as accurate and more time efficient when measuring dental arch dimensions. Caliper measurements were regarded as the "gold standard," against which other measurement techniques are compared.

When scanned images of dental cast and conventional study casts were compared, it has been shown that the measurements obtained from the scanned dental cast were smaller than dental cast measurements [Table 1]. These differences might be attributed to the difficulty of measuring a three dimensional (3D) model in two dimensions because of the convex structure of the teeth, the curve of speed, and differences in the inclination of the teeth. ${ }^{[9]}$ This is in accordance with the study conducted by Schirmer and Wiltshire who also found that scanned dental casts measurements were smaller than the dental casts. ${ }^{[10]}$ When the reliability and validity were examined by comparisons between measurements taken on the scanned dental casts and from conventional dental cast, it showed that the measurements obtained from the scanned dental casts demonstrated a statistically significant degree of correlation with dental cast measurements $(P<0.05)$ [Graph 1$]$.

It showed that the measurements obtained from the photographs demonstrated a statistically 
Table 1: Mean, standard deviation, std error, mean difference and interclass correlation for the measurements between dental cast and scanned images of dental cast

\begin{tabular}{|c|c|c|c|c|c|c|c|c|c|}
\hline \multirow[t]{2}{*}{ Variable } & \multicolumn{2}{|c|}{ CAST } & \multicolumn{2}{|c|}{ Mcan } & \multirow[t]{2}{*}{ Standard error } & \multirow{2}{*}{$\begin{array}{l}\text { Difference } \\
\text { Cast-scan } \\
\end{array}$} & \multirow[t]{2}{*}{ t-test } & \multicolumn{2}{|c|}{$\begin{array}{l}\text { Interclass } \\
\text { correlation }\end{array}$} \\
\hline & Mean & SD & Mean & SD & & & & $\mathbf{r}$ & Sig. \\
\hline UR 1 & 8.32 & 0.42 & 8.10 & 0.42 & 0.02 & 50 & 12.08 & 0.95 & $0.001^{* * *}$ \\
\hline UR 2 & 6.49 & 0.44 & 6.29 & 0.43 & 0.02 & 50 & 10.38 & 0.95 & $0.001 * * *$ \\
\hline UR 3 & 7.39 & 0.47 & 7.13 & 0.53 & 0.02 & 50 & 13.30 & 0.96 & $0.001 * * *$ \\
\hline UR 4 & 6.77 & 0.34 & 6.56 & 0.42 & 0.03 & 50 & 7.30 & 0.88 & $0.001^{* * * *}$ \\
\hline UR 5 & 6.42 & 0.51 & 6.26 & 0.47 & 0.03 & 50 & 5.22 & 0.91 & $0.001 * * *$ \\
\hline UR 6 & 10.06 & 0.65 & 9.81 & 0.61 & 0.02 & 50 & 12.12 & 0.97 & $0.001^{* * *}$ \\
\hline UL 1 & 8.36 & 0.42 & 8.13 & 0.43 & 0.02 & 50 & 10.73 & 0.93 & $0.001^{* * *}$ \\
\hline UL 2 & 6.47 & 0.43 & 6.25 & 0.47 & 0.02 & 50 & 10.17 & 0.94 & $0.001 * * *$ \\
\hline UL 3 & 7.46 & 0.48 & 7.23 & 0.45 & 0.02 & 50 & 13.26 & 0.96 & $0.001 * * *$ \\
\hline UL 4 & 6.73 & 0.38 & 6.54 & 0.37 & 0.02 & 50 & 7.61 & 0.89 & $0.001 * * *$ \\
\hline UL 5 & 6.37 & 0.45 & 6.24 & 0.47 & 0.03 & 50 & 4.54 & 0.89 & $0.001 * * *$ \\
\hline UL 6 & 9.99 & 0.68 & 9.81 & 0.65 & 0.03 & 50 & 5.70 & 0.94 & $0.001 * * *$ \\
\hline LL 1 & 5.29 & 0.35 & 5.14 & 0.32 & 0.02 & 50 & 6.85 & 0.89 & $0.001 * * *$ \\
\hline LL 2 & 5.86 & 0.41 & 5.65 & 0.42 & 0.01 & 50 & 14.87 & 0.97 & $0.001 * * *$ \\
\hline LL 3 & 6.55 & 0.43 & 6.26 & 0.41 & 0.02 & 50 & 15.43 & 0.95 & $0.001^{* * * *}$ \\
\hline LL 4 & 6.75 & 0.41 & 6.53 & 0.42 & 0.03 & 50 & 7.34 & 0.87 & $0.001^{* * * *}$ \\
\hline LL 5 & 6.71 & 0.37 & 6.52 & 0.42 & 0.02 & 50 & 8.91 & 0.93 & $0.001 * * *$ \\
\hline LL 6 & 10.69 & 0.52 & 10.47 & 0.54 & 0.03 & 50 & 6.58 & 0.90 & $0.001 * * *$ \\
\hline LR 1 & 5.28 & 0.36 & 5.15 & 0.34 & 0.03 & 50 & 4.58 & 0.82 & $0.001 * * *$ \\
\hline LR 2 & 5.88 & 0.42 & 5.72 & 0.48 & 0.03 & 50 & 5.79 & 0.92 & $0.001 * * *$ \\
\hline LR 3 & 6.59 & 0.37 & 6.43 & 0.43 & 0.02 & 50 & 6.94 & 0.93 & $0.001^{* * * *}$ \\
\hline LR 4 & 6.77 & 0.39 & 6.55 & 0.38 & 0.03 & 50 & 8.82 & 0.89 & $0.001 * * *$ \\
\hline LR 5 & 6.70 & 0.36 & 6.52 & 0.38 & 0.03 & 50 & 6.13 & 0.84 & $0.001 * * *$ \\
\hline LR 6 & 10.62 & 0.52 & 10.36 & 0.51 & 0.04 & 50 & 6.98 & 0.86 & $0.001 * * *$ \\
\hline UIMW & 50.21 & 2.26 & 49.73 & 2.31 & 0.03 & 50 & 13.78 & 0.99 & $0.001^{* * * *}$ \\
\hline UICW & 34.56 & 2.54 & 34.15 & 2.45 & 0.04 & 50 & 10.16 & 0.99 & $0.001 * * *$ \\
\hline LIMW & 43.99 & 3.25 & 43.39 & 3.30 & 0.09 & 50 & 6.17 & 0.97 & $0.001 * * *$ \\
\hline LICW & 25.79 & 2.78 & 25.53 & 2.72 & 0.06 & 50 & 4.17 & 0.98 & $0.001 * * *$ \\
\hline
\end{tabular}

$* P<0.05 ; * * P<0.01 ; * * * P<0.001$ and NS represents values are non significant

significant high degree of correlation with dental cast measurements $(P<0.05)$ [Graph 2]. Despite the high reliability, paired $t$-test revealed some statistical differences in the validity of two methods. However, systematic error was observed when determining the lower left canine width, upper left molar width, and lower intercanine width. This high sensitivity to identify these small differences could be related to the large sample size used in the paired $t$-test [Table 2]. Since the average difference was close to or below the limit of resolution of the human eye, these minor differences must be considered clinically insignificant. Another possible reason may be due to difficulty in creating a standardized position for the mirror in this area or the angle formed between the lens and mirror when obtaining the occlusal photograph. ${ }^{[4]}$ Hence, this method shows excellent reliability and only minor errors. These data reinforce the use of this method as a reliable way of obtaining tooth size and dental arch dimensions. The present study is in accordance with the study conducted by Normando et al. ${ }^{[4]}$ and Gholston. ${ }^{[7]}$ Since the mean values of dental arch measurements obtained from the 
Table 2: Showing mean, standard deviation, std error, mean difference and interclass correlation for the measurements between dental cast and photographs

\begin{tabular}{|c|c|c|c|c|c|c|c|c|c|}
\hline \multirow[t]{2}{*}{ Variable } & \multicolumn{2}{|c|}{ CAST } & \multicolumn{2}{|c|}{ Photo } & \multirow[t]{2}{*}{ Standard error } & \multirow{2}{*}{$\begin{array}{l}\text { Difference } \\
\text { Cast-photo }\end{array}$} & \multirow[t]{2}{*}{ t-test } & \multicolumn{2}{|c|}{$\begin{array}{l}\text { Interclass } \\
\text { correlation }\end{array}$} \\
\hline & Mean & SD & Mean & SD & & & & $\mathbf{r}$ & Sig. \\
\hline UR 1 & 8.32 & 0.42 & 8.18 & 0.45 & 0.01 & 50 & 10.17 & 0.97 & $0.001 * * *$ \\
\hline UR 2 & 6.49 & 0.44 & 6.39 & 0.46 & 0.02 & 50 & 6.31 & 0.97 & $0.001 * * *$ \\
\hline UR 3 & 7.39 & 0.47 & 7.23 & 0.51 & 0.02 & 50 & 8.60 & 0.96 & $0.001 * * *$ \\
\hline UR 5 & 6.42 & 0.51 & 6.37 & 0.49 & 0.02 & 50 & 2.59 & 0.96 & $0.012^{* *}$ \\
\hline UR 6 & 10.06 & 0.65 & 9.98 & 0.61 & 0.03 & 50 & 2.60 & 0.93 & $0.012 * *$ \\
\hline UL 1 & 8.36 & 0.42 & 8.23 & 0.44 & 0.02 & 50 & 7.35 & 0.95 & $0.001 * * *$ \\
\hline UL 2 & 6.47 & 0.43 & 6.37 & 0.44 & 0.02 & 50 & 5.91 & 0.96 & $0.001^{* * *}$ \\
\hline UL 3 & 7.46 & 0.48 & 7.32 & 0.46 & 0.02 & 50 & 6.74 & 0.95 & $0.001^{* * *}$ \\
\hline UL 5 & 6.37 & 0.45 & 6.32 & 0.42 & 0.02 & 50 & 2.54 & 0.94 & $0.014^{* *}$ \\
\hline UL 6 & 9.99 & 0.68 & 9.97 & 0.64 & 0.03 & 50 & 0.83 & 0.94 & $0.40 \mathrm{NS}$ \\
\hline LL 1 & 5.29 & 0.35 & 5.23 & 0.37 & 0.02 & 50 & 3.54 & 0.93 & $0.001 * * *$ \\
\hline LL 2 & 5.86 & 0.41 & 5.74 & 0.41 & 0.02 & 50 & 7.85 & 0.96 & $0.001 * * *$ \\
\hline LL 3 & 6.55 & 0.43 & 6.39 & 0.45 & 0.02 & 50 & 9.61 & 0.96 & $0.064 \mathrm{NS}$ \\
\hline LL 4 & 6.75 & 0.41 & 6.59 & 0.40 & 0.02 & 50 & 7.46 & 0.93 & $0.001^{* * * *}$ \\
\hline LL 5 & 6.71 & 0.37 & 6.55 & 0.38 & 0.02 & 50 & 8.13 & 0.93 & $0.001^{* * * *}$ \\
\hline LL 6 & 10.69 & 0.52 & 10.57 & 0.49 & 0.02 & 50 & 5.74 & 0.95 & $0.001^{* * *}$ \\
\hline LR 1 & 5.28 & 0.36 & 5.22 & 0.36 & 0.02 & 50 & 3.31 & 0.92 & $0.001^{* * *} *$ \\
\hline LR 2 & 5.88 & 0.42 & 5.72 & 0.47 & 0.03 & 50 & 5.63 & 0.90 & $0.001^{* * * *}$ \\
\hline LR 3 & 6.59 & 0.37 & 6.45 & 0.42 & 0.03 & 50 & 4.04 & 0.90 & $0.001^{* * * *}$ \\
\hline LR 6 & 10.62 & 0.52 & 10.47 & 0.48 & 0.02 & 50 & 6.74 & 0.95 & $0.001^{* * * *}$ \\
\hline UIMW & 50.21 & 2.26 & 49.86 & 2.14 & 0.05 & 50 & 6.70 & 0.98 & $0.001 * * *$ \\
\hline UICW & 34.56 & 2.54 & 44.10 & 3.44 & 0.04 & 50 & 4.07 & 0.99 & $0.001^{* * * *}$ \\
\hline LIMW & 43.99 & 3.25 & 43.85 & 3.21 & 0.03 & 50 & 3.79 & 0.99 & $0.001^{* * *} *$ \\
\hline LICW & 25.79 & 2.78 & 25.71 & 2.71 & 0.04 & 50 & 1.89 & 0.99 & $0.064 \mathrm{NS}$ \\
\hline
\end{tabular}

$* P<0.05$; ** $P<0.01$; *** $P<0.001$ and NS represents values are non significant

photographs were closer to that of conventional dental casts as compared to that of scanned dental casts. Hence, occlusal photograph is a reliable and valid instrument for measuring the mesiodistal tooth width and dental arch dimensions.

The camera permits the quantification of intraarch dental characteristics. The 3D morphology of the teeth and dental arches can be described in terms of two-dimensional $\mathrm{X}$ and $\mathrm{Y}$ rectangular coordinates. Data collected in this fashion are extremely conducive to electronic reduction and computer analysis. Clinical uses, such as checking patient's arch form and symmetry and indirect archwire fabrication, have been described by Chanda. ${ }^{[11]}$ It could be used for fabricating archwires when the lingual appliance technique is used. However, the research potential of this camera has yet to be explored. Generation of statistically relevant interpopulation data could be accomplished quite cheaply and conveniently. For example, the taxonomic significance of human dental arches has been documented. ${ }^{[12]}$ With this camera, data on the arch size and shape of extant and extinct populations are easily retrieved. In addition, 


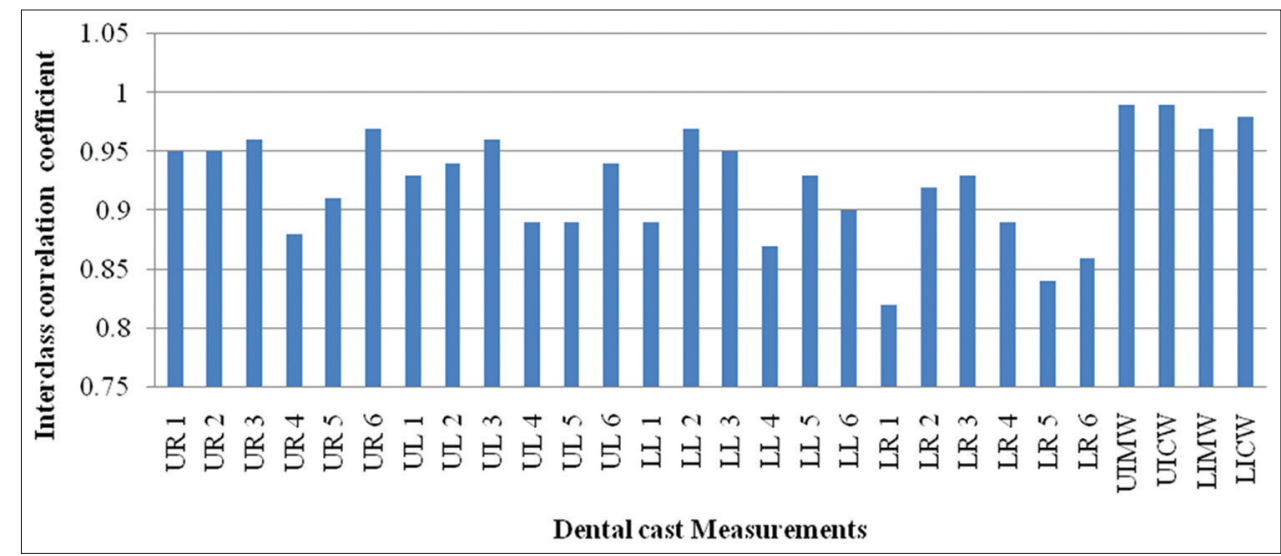

Graph 1: The correlation between the measurements obtained from dental cast and scanned images of dental cast

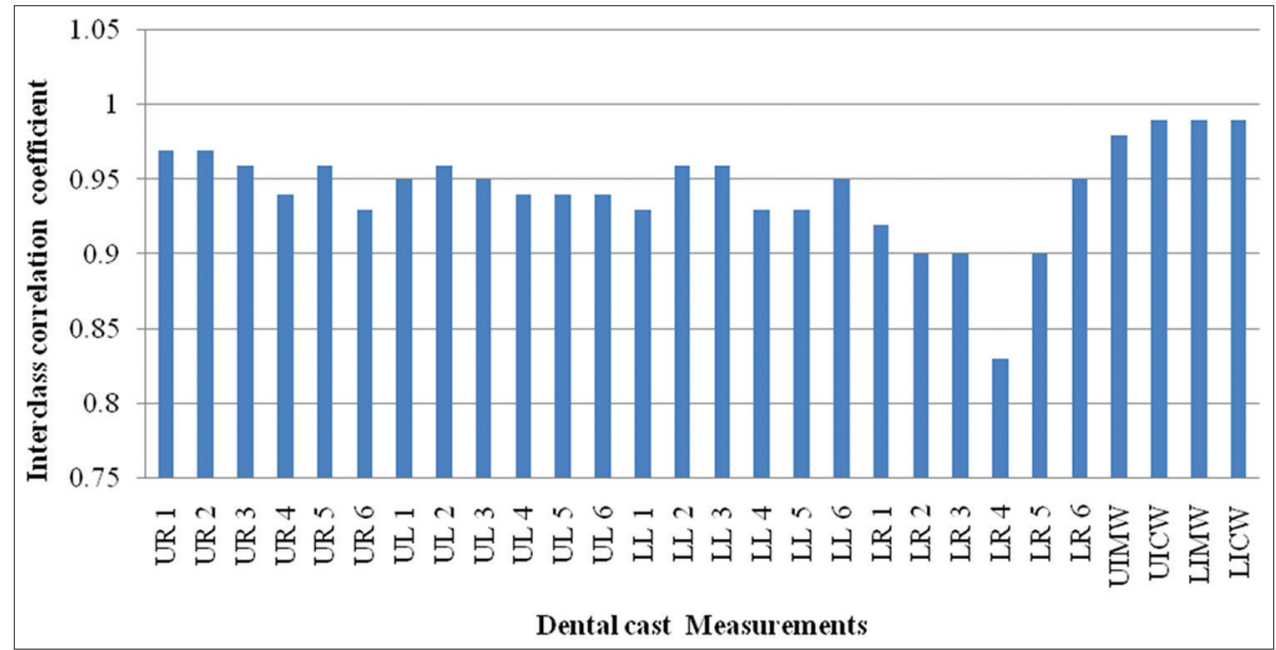

Graph 2: The correlation between the measurements obtained from dental cast and photographs

epidemiologic studies in the field would be greatly facilitated, and standardized information would be obtained. This new method of measurement can also help collect contemporary data on the growth and development of the dental arches. These data could be useful in embellishing existing models which can simulate the effects of orthodontic treatment on arch growth. ${ }^{[13]}$ The collection of these data would not be wedded to dental casts. The production of dental casts is labor intensive. Substantial amounts of materials and laboratory support are essential. The storage and management of these casts can be problematic in large-scale studies.

\section{CONCLUSION}

The following conclusions were drawn from the present study.
- The dental arch measurements obtained from the photographs showed high accuracy and reproducibility as compared to scanned images of dental cast.

- With the exception of mesiodistal width of lower left canine, upper left molar, and lower intercanine width, the photogrammetric method is a reliable instrument for clinical application to measure the dental arch dimensions and tooth size.

\section{REFERENCES}

1. Zilberman O, Huggare JA, Parikakis KA. Evaluation of the validity of tooth size and arch width measurements using conventional and three-dimensional virtual orthodontic models. Angle Orthod 2003;73:301-6.

2. Paredes V, Gandia JL, Cibrian R. New, fast, and accurate 
procedure to calibrate a 2-dimensional digital measurement method. Am J Orthod Dentofacial Orthop 2005;127:518-9.

3. Champagne M. Reliability of measurements from photocopies of study models. J Clin Orthod 1992;26:648-50.

4. Normando D, da Silva PL, Mendes ÁM. A clinical photogrammetric method to measure dental arch dimensions and mesio-distal tooth size. Eur J Orthod 2011;33:721-6.

5. Tomassetti JJ, Taloumis LJ, Denny JM, Fischer JR Jr. A comparison of 3 computerized Bolton tooth-size analyses with a commonly used method. Angle Orthod 2001;71:351-7.

6. Proffit WR. Contemporary Orthodontics. $3^{\text {rd }}$ ed. St Louis, Mo: Mosby; 2000. p. 169-70.

7. Gholston LR. Reliability of an intraoral camera: Utility for clinical dentistry and research. Am J Orthod 1984;85:89-93.
8. Ho CT, Freer TJ. A computerized tooth-width analysis. J Clin Orthod 1999;33:498-503.

9. Mullen SR, Martin CA, Ngan P, Gladwin M. Accuracy of space analysis with emodels and plaster models. Am J Orthod Dentofacial Orthop 2007;132:346-52.

10. Schirmer UR, Wiltshire WA. Manual and computeraided space analysis: A comparative study. Am J Orthod Dentofacial Orthop 1997;112:676-80.

11. Chanda LH. The orthoscan camera. J Clin Orthod 1973;7:363-7.

12. Lavelle CL. A study of the taxonomic significance of the dental arch. Am J Phys Anthropol 1977;46:415-21.

13. Biggerstaff RH. Computerized diagnostic setups and simulations. Angle Orthod 1970;40:28-36 